\title{
Agreement Between Self-reports and On-Site Inspections of Compliance With a Workplace Smoking Ban
}

Citation for published version (APA):

Verdonk-Kleinjan, W. M. I., Rijswijk, P. C. P., Candel, M. J. J. M., de Vries, H., \& Knibbe, R. A. (2012).

Agreement Between Self-reports and On-Site Inspections of Compliance With a Workplace Smoking Ban. Nicotine \& Tobacco Research, 14(9), 1121-1125. https://doi.org/10.1093/ntr/ntr295

Document status and date:

Published: 01/09/2012

DOI:

10.1093/ntr/ntr295

Document Version:

Publisher's PDF, also known as Version of record

\section{Document license:}

Taverne

Please check the document version of this publication:

- A submitted manuscript is the version of the article upon submission and before peer-review. There can be important differences between the submitted version and the official published version of record.

People interested in the research are advised to contact the author for the final version of the publication, or visit the DOI to the publisher's website.

- The final author version and the galley proof are versions of the publication after peer review.

- The final published version features the final layout of the paper including the volume, issue and page numbers.

Link to publication

\footnotetext{
General rights rights.

- You may freely distribute the URL identifying the publication in the public portal. please follow below link for the End User Agreement:

www.umlib.nl/taverne-license

Take down policy

If you believe that this document breaches copyright please contact us at:

repository@maastrichtuniversity.nl

providing details and we will investigate your claim.
}

Copyright and moral rights for the publications made accessible in the public portal are retained by the authors and/or other copyright owners and it is a condition of accessing publications that users recognise and abide by the legal requirements associated with these

- Users may download and print one copy of any publication from the public portal for the purpose of private study or research.

- You may not further distribute the material or use it for any profit-making activity or commercial gain

If the publication is distributed under the terms of Article $25 \mathrm{fa}$ of the Dutch Copyright Act, indicated by the "Taverne" license above, 


\title{
Brief Report
}

\section{Agreement Between Self-reports and On-Site Inspections of Compliance With a Workplace Smoking Ban}

\author{
Wendy M. I. Verdonk-Kleinjan, B.Sc., ${ }^{1}$ Pieter C. P. Rijswijk, M.Sc., ${ }^{2}$ Math J. J. M. Candel, Ph.D., ${ }^{3}$ Hein de Vries, Ph.D., ${ }^{4}$ \\ \& Ronald A. Knibbe, Ph.D. ${ }^{4}$ \\ ${ }^{1}$ Food and Consumer Product Safety Authority, Utrecht, The Netherlands \\ ${ }^{2}$ Food and Consumer Product Safety Authority, Eindhoven, The Netherlands \\ ${ }^{3}$ Department of Methodology and Statistics, Faculty of Health, Medicine and Life Sciences, University Maastricht, Maastricht, The Netherlands \\ ${ }^{4}$ Department of Health Education and Promotion, Faculty of Health, Medicine and Life Sciences, University Maastricht, Maastricht, \\ The Netherlands
}

Corresponding Author: Wendy M. I. Verdonk-Kleinjan, B.Sc., Food and Consumer Product Safety Authority, Directorate Staff and Control, PO Box 43006, 3540 AA Utrecht, The Netherlands. Telephone: +31-88-2233333; E-mail: wendy.verdonk-kleinjan@vwa.nl

Received April 7, 2011; accepted November 12, 2011

\section{Abstract}

Introduction: This study compares self-reports on compliance with a workplace smoking ban with on-site inspections of the same workplace, in the Netherlands, to assess the validity of selfreported compliance by employees.

Methods: A total of 360 companies had participated in the telephone survey (in October and November 2006) and were also visited by inspectors directly after the survey to establish compliance. The sampling frame included companies with 5 or more employees, stratified according to the number of employees and type of economic activity. We calculated the agreement, the under- or overestimation and the predictive values, and explored nonresponse research.

Results: The percent agreement on compliance between the two measures was $77.5 \%$, the McNemar test was not significant, and the agreement coefficient with first order correction was .68, indicating moderately strong agreement. Furthermore, the results indicate a slight overestimation of compliance. Concerning the predictive values, we found most variance among the self-reported noncompliance: $55.2 \%$ of those reporting noncompliance did in fact comply.

Conclusions: This study allows to conclude that self-reports on compliance with a workplace smoking ban are largely valid and that social desirability is negligible. For agencies enforcing the workplace smoking ban, these results indicate that a strategy to identify noncompliance among responding companies might be useful. Moreover, such a strategy reduces the burden of inspecting among complying companies.

\section{Introduction}

In the Netherlands, the workplace smoking ban was implemented on January 1, 2004, with the exception of the hospitality sector. The act banned smoking inside but allowed to provide designated smoking rooms. The Dutch Food and Consumer Product Safety Authority (FCPSA) became legally responsible to monitor compliance. The FCPSA has the authority to impose fines in case of noncompliance. These fines start at 300 euro and increase to a maximum of 2,400 euro in case of continued noncompliance.

For an effective enforcement program, it is necessary to have insight in compliance rates. Although use of self-report is a common method when examining compliance (Borland et al., 2006; Gilpin, Farkas, Emery, Ake, \& Pierce, 2002; Heloma \& Jaakkola, 2003; Hyland et al., 2009), this method can be biased by "social desirability" (Holbrook, Green, \& Krosnick, 2003), which is defined as the tendency of respondents to reply in a manner that will be viewed favorably by others. In this case, the avoidance of legal consequences (in case of noncompliance) is a part of social desirability. In general, social desirability will take the form of overreporting good behavior or underreporting bad behavior. The present study compares self-reports on compliance with a workplace smoking ban with on-site inspections of the same workplace.

In 2006, a telephone interview was held with employees responsible for implementation of the workplace smoking ban regulation. Independent of this survey, inspectors of the FCPSA organization conducted on-site inspections of the workplace smoking ban. The present study uses the outcomes of the on-site inspections to assess the validity of self-reported compliance by employees.

\section{Methods}

The sampling frame for the telephone survey included Dutch companies with five or more employees. For the telephone survey, a random sample of 4,634 companies stratified according to the number of employees $(5-9,10-99,>100)$ and type of 


\section{Measuring compliance with a workplace smoking ban}

economic activity (i.e., agriculture, industry, education) was taken from the Netherlands database of registered companies. From the telephone survey sample, a second random sample was taken for on-site inspections, with the exception of companies in the hospitality industry as that sector was, at that time, excluded from the workplace smoking ban. This second sample was smaller than the first because nonresponse was not expected, since companies are obliged to cooperate with the inspections performed by the FCPSA. During October and November 2006, the telephone survey was performed by a commercial market research organization. Directly after this survey, the FCPSA conducted on-site inspections up to February 2007. Anonymity of the companies that participated in the telephone survey was guaranteed, and it was unknown to the FCPSA, which companies had participated in the telephone survey. Of the 4,634 companies, 3,925 companies were reached by telephone and $2,201(56.1 \%)$ were willing to complete an interview; this was reduced to $2,018(55.0 \%)$ companies after excluding the hospitality industry. Those companies not willing to participate were asked the same question about their smoking policy. Of the 2,018 companies which completed an interview, 360 were also visited by inspectors to establish compliance with the workplace smoking ban. For the present study, we made three categories of companies: public sector (e.g., schools, hospitals, public administration, social services), service sector, and industry. We use the general term "company" to cover both public and for-profit enterprises. This sample of 360 companies shows a similar distribution in terms of the size of the company, that is, $31.9 \%$ (5-9 employees), 54.7\% (10-99 employees), and 13.3\% (>100 employees), and economic activity, that is, $17.2 \%$ (public sector), $50.3 \%$ (service sector), and $32.5 \%$ (industry sector), to the companies selected for on-site inspections $(n=1,389)$, that is, $35.4 \%$ (5-9 employees), $54.8 \%$ (10-99 employees), and 9.8\% (>100 employees), and 22.6\% (public sector), $46.6 \%$ (service sector), and $30.8 \%$ (industry sector), as well as to the companies which completed an interview $(n=2,018), 33.9 \%$ (5-9 employees), $54.1 \%$ (10-99 employees), and $12.0 \%$ (>100 employees), and $24.3 \%$ (public sector), $44.7 \%$ (service sector), and $31.0 \%$ (industry sector).

In the telephone interview, compliance with the workplace smoking ban was measured by the question "Which of the following descriptions reflect the current smoking policy in your company?" The answers "complete smoking ban" and "general smoking ban with lockable smoking rooms, avoidable for nonsmokers" indicate compliance with the legislation and all other answers (i.e., "general smoking ban with nonlockable smoking areas," "limited smoking ban, whereby smoking is prohibited in some places within the company," and "no smoking regulation") indicate noncompliance. The inspectors used systematic observation, which includes control of the smoking policy (such as having no-smoking rules and having no-smoking signs) and checks on nonsmoking (such as there being no smokers and no ashtrays) to classify the workplaces into those complying and not complying with the smoking ban.

To validate the accuracy of self-reported compliance, we used the combined dataset of 360 companies. First, we calculated the percent agreement, McNemar's test, and the agreement coefficient with first order correction $\left(\mathrm{AC}_{1}\right)$ for the whole group and stratified according to company size (5-9 employees, 10-99 employees, and $>100$ employees) and economic activity (public sector, service sector, and industry). The $\mathrm{AC}_{1}$ coefficient expresses the agreement between the two collection methods but, contrary to the percent agreement, corrects for agreement due to chance. Furthermore, compared with the traditional kappa measure, which also corrects for agreement due to chance, the $\mathrm{AC}_{1}$ coefficient gives less biased estimates of the true intermethod agreement when the prevalence of an event is high or low (Gwet, 2008). In these cases, the kappa clearly underestimates the true agreement. Since we expected the compliance to be much more than $50 \%$, we preferred to calculate the $\mathrm{AC}_{1}$ coefficient instead of the kappa. For the $\mathrm{AC}_{1}$ coefficient, the following cutoffs were used: A score of .8 or more is very strong agreement, .6-.8 indicates moderately strong agreement, .3-.6 is fair agreement, and a score of .3 or less is poor agreement (Chan, 2003). To test whether the percent agreement was different for companies of different size and for companies categorized according to economic activity, chi-square tests were performed, each time comparing two types of companies in terms of agreement.

Second, we compared the compliance based on the selfreports and compliance based on the on-site inspections to determine under- or overestimation. Finally, we calculated the predictive values, indicating the probability that self-reported compliance or noncompliance has been confirmed by on-site inspections (Altman \& Bland, 1994). The predictive values also allow to estimate whether the error of overreporting compliance or underreporting compliance dominates nonagreement.

In relation to the nonresponse research, we used the companies willing to answer only one question as a proxy for nonresponders. Differences in compliance according to selfreport and on-site inspection between companies answering all questions and those answering only one question are presented. Furthermore, we analyzed differences in on-site inspections between companies that participated in the whole interview and companies that did not. We also calculated the percent agreement, McNemar's test, the $\mathrm{AC}_{1}$ and the predictive values for those companies $(n=120)$ that answered only the question about their smoking policy. Data were analyzed using SPSS 16.0 for Windows.

\section{Results}

Table 1 presents the results of the 360 companies: The raw percent agreement between the two data collection methods was $77.5 \%$. In $70.3 \%$ of the cases, self-reported compliance matched with compliance based on the on-site inspections, and in $7.2 \%$ of the cases self-reported noncompliance matched with on-site inspection. The McNemar test was not significant ( $p>.05$ ), which indicates no difference between the self-reported and observed compliance by on-site inspections. The $\mathrm{AC}_{1}$ is .68 , indicating moderately strong agreement (Chan, 2003). When focusing on companies of different size (Table 1), there is no significant difference in percent agreement. The McNemar test found no differences between self-reported compliance and compliance assessed by the FCPSA. For a stratification of companies according to the type of economic activity, we assessed a significantly higher percent agreement among the public sector compared with the industry. Only for the service sector did McNemar's test turn out to be significant, which indicates that the self-reported compliance is higher than the observed compliance for this type of company. 
Nicotine \& Tobacco Research, Volume 14, Number 9 (September 2012)

\section{Table 1. Data on Agreement Between Compliance Ratings, n (\%)}

\begin{tabular}{|c|c|c|c|c|c|c|c|}
\hline & & Inspection & & & Percent & McNemar's test & \\
\hline & Self-reports & Compliance (\%) & Noncompliance (\%) & & agreement & $p$ value & $\mathrm{AC}_{1}^{\mathrm{a}}$ \\
\hline Overall $(n=360)$ & Compliance & 70.3 & 13.6 & 83.9 & 77.5 & .075 & .68 \\
\hline & Noncompliance & 8.9 & 7.2 & 16.1 & & & \\
\hline & & 79.2 & 20.8 & 100 & & & \\
\hline Size of the companies & & & & & & & \\
\hline 5-9 employees $(n=115)$ & Compliance & 67.0 & 14.8 & 81.7 & 75.7 & .345 & .64 \\
\hline & Noncompliance & 9.6 & 8.7 & 18.3 & & & \\
\hline & & 76.5 & 23.5 & 100 & & & \\
\hline 10-99 employees $(n=197)$ & Compliance & 71.6 & 13.2 & 84.8 & 79.2 & .118 & .70 \\
\hline & Noncompliance & 7.6 & 7.6 & 15.2 & & & \\
\hline & & 79.2 & 20.8 & 100 & & & \\
\hline$>100$ employees $(n=48)$ & Compliance & 72.9 & 12.5 & 85.4 & 75.0 & 1.000 & .67 \\
\hline & Noncompliance & 12.5 & 2.1 & 14.6 & & & \\
\hline & & 85.4 & 14.6 & 100 & & & \\
\hline Sector & & & & & & & \\
\hline Public sector $(n=62)$ & Compliance & 87.1 & 8.1 & 95.2 & 87.1 & .727 & .85 \\
\hline & Noncompliance & 4.8 & 0.0 & 4.8 & & & \\
\hline & & 91.9 & 8.1 & 100 & & & \\
\hline Service sector $(n=181)$ & Compliance & 65.7 & 16.6 & 82.3 & 76.7 & $.009^{*}$ & .64 \\
\hline & Noncompliance & 6.6 & 11.0 & 17.7 & & & \\
\hline & & 72.4 & 27.6 & 100 & & & \\
\hline Industry $(n=117)$ & Compliance & 68.4 & 12.0 & 80.3 & 73.5 & .719 & .62 \\
\hline & Noncompliance & 14.5 & 5.1 & 19.7 & & & \\
\hline & & 82.9 & 17.1 & 100 & & & \\
\hline
\end{tabular}

Note. $\mathrm{AC}_{1}=$ the agreement coefficient with first order correction.

${ }^{a}$ Cutoffs for $\mathrm{AC}_{1}: .8$ or more $=$ very strong agreement, $.6-.8=$ moderately strong agreement, $.3-.6=$ fair agreement, .3 or less $=$ poor agreement (Chan, 2003).

${ }^{*} p<.01$.

In the telephone survey, $83.9 \%$ reported compliance with the smoke-free workplace legislation, whereas during the on-site inspection, the FCPSA established compliance for $79.2 \%$ of the companies. This result indicates a slight overestimation of compliance by $4.7 \%$ if one uses self-reports rather than on-site inspections.

Finally, we calculated the predictive values. The positive predictive value, the chance that self-reported compliance is confirmed by on-site inspections, is 0.838 , indicating that $83.8 \%$ of the companies that reported compliance did indeed comply with the workplace smoking ban legislation and $16.2 \%$ did not. The negative predictive value, the chance that self-reported noncompliance is confirmed by on-site inspections, is 0.448 , which means that for $44.8 \%$ of the companies that reported noncompliance, this was confirmed by on-site inspections. However, 55.2\% of the companies reporting noncompliance did in fact comply according to the on-site inspections. This indicates that a higher proportion of reported noncompliance was not confirmed compared with the proportion of reported compliance.

Nonresponse analysis showed that there were no significant differences in self-reported compliance between responding companies $(83 \% ; n=2,018)$ and companies willing to answer only one question $(80.7 \% ; n=576)$ nor in reported compliance according to on-site inspections for responding companies
$(79.2 \% ; n=360)$ and for companies willing to answer only one question $(76.7 \% ; n=120)$. Comparing on-site inspections between the groups of full responders and the group of partial and nonresponders showed no significant differences between companies that completed the interview $(79.2 \% ; n=360)$ and companies that did not $(77.0 \% ; n=1,029)$. When focusing on agreement measures among the companies that were willing to answer one question, we found a raw percentage agreement of $70 \%$ and an $\mathrm{AC}_{1}$ of .56 indicating fair agreement (Chan, 2003). The McNemar test was not significant $(p>.05)$, which indicates no difference between the self-reported and observed compliance by on-site inspections in this group. The positive predictive value is 0.780 and is in line with the sample of full responders, and the negative predictive value is 0.300 , which is lower than that of the full responders.

\section{Discussion}

Our main question was to assess the validity of self-reported compliance. The outcomes show that there is large agreement between compliance according to self-reports and on-site inspections. Further, for all companies together, no significant difference in compliance rates was found between both methods (i.e., self-reports and observations by inspectors of the FCPSA) and both yield comparable compliance rates. These results indicate 


\section{Measuring compliance with a workplace smoking ban}

that self-reported compliance by employees is a valid method to assess compliance of the workplace smoking ban.

However, for companies in the service sector, the results of the self-reported compliance did not agree with the observed compliance. Furthermore, we have to take into account that compared with the original sample of all interviewed companies $(n=2,018)$ and all on-site inspections $(n=1,389)$, companies in the public sector were underrepresented in the sample for which both self-reports and on-site inspections $(n=360)$ were available. As the $\mathrm{AC}_{1}$ is higher in the public sector (.85) than in the service sector (.64) and industry (.62), this probably means that for the total population of enterprises, the $\mathrm{AC}_{1}$ is somewhat underestimated.

Finally, nonresponse analysis showed comparable levels of compliance between the responding and partial responding groups and between the responding group and the nonresponding and partial responding groups. Furthermore, McNemar's test of partial responders showed that self-reported compliance did not differ significantly from the observed compliance. These results do not indicate that among nonresponders, differences in compliance according to self-report and on-site inspection are larger than among enterprises fully cooperating with an interview.

We compared the results of our study with two different kinds of studies, one that is methodologically comparable and others related to smoking legislation. In the first comparison, Hurd, Mayer, Woodruff, Belch, \& Patel (2006) found similar percent raw agreements for compliance with indoor tanning legislation between measures based on self-reports and based on on-site visits: $71.3 \%$ for the frequency allowed to tan and $76.3 \%$ for parentally required consent. However, in that study, the $\mathrm{AC}_{1}$ was lower: .57 and .63 , respectively. In the second comparison, we found a validation study of self-reported environmental tobacco smoke, which is used as compliance indicator of worksite smoking policies, indicating a substantial correlation with environmental measures as nicotine $(r=.65 ; p<.001$; Willemsen, Brug, Uges, \& Vos, de Wael, 1997).

Taking the results of the on-site inspections as the more objective measure, the results indicate that the (overall) compliance based on self-reports is somewhat overreported (4.7\%). This is probably due to answers being based on social desirability. Holbrook et al. (2003) describe that people attempt to construct favorable images of themselves when the reporting circumstances assure anonymity, such as the telephone interviews used in the present study.

Another interesting and surprising outcome concerns the predictive values, whereby most variance was found among the self-reported noncompliance. According to the on-site inspection, $55.2 \%$ of the companies reporting noncompliance did in fact comply. A possible reason for this is that there might be another mechanism, which is almost the opposite of social desirability, claiming noncompliance while complying. Respondents who had insufficient knowledge on this subject, or on how the ban was actually implemented, may have "played safe" by giving a negative answer. Another explanation could be that companies started to implement the workplace smoking ban after being reminded by the interview that they did not yet comply. In our nonresponse research, this phenomenon was stronger in companies willing to answer only one question. Up to $70 \%$ of those reporting noncompliance did in fact comply, which suggests that the proposed mechanism, that is, giving a negative answer because they believe they have insufficient knowledge, might work even stronger and might influence nonparticipation in the whole interview.

This study allows to conclude that self-reports on compliance with a workplace smoking ban are largely valid and that social desirability is negligible. For agencies enforcing the workplace smoking ban, these results indicate that a strategy to identify noncompliance among responding companies might be useful. Table 1 shows that concentrating the inspection on those reporting noncompliance increases the possibility to identify noncompliance rather than focusing on companies reporting compliance, of which only a small percentage do not in fact comply. It is clear that preliminary screening reduces the burden of inspection of the large majority of companies in which the likelihood of noncompliance is comparatively low.

The answer to the question as to how such preliminary screening could be implemented probably lies with the innovation programs in the Netherlands aimed at increasing the effectiveness of enforcement agencies. One such innovation is the use of a web-based survey by enforcement agencies to collect data, which helps to increase risked-based supervision (Inspectie voor de Gezondheidszorg, 2010). However, as soon as companies know about such a strategy, they might try to reduce the chance of on-site inspection by reporting compliance. Whether such behavior in fact occurs should be investigated.

\section{Funding}

None declared.

\section{Declaration of Interests}

None declared.

\section{References}

Altman, D. G., \& Bland, J. M. (1994). Diagnostic tests 2: Predictive values. British Medical Journal, 309, 102. doi:10.1136/bjm.309. 6947.102

Borland, R., Yong, H. H., Siahpush, M., Hyland, A., Campbell, S., Hastings, G., et al. (2006). Support for and reported compliance with smoke-free restaurants and bars by smokers in four countries: Findings from the International Tobacco Control (ITC) Four Country Survey. Tobacco Control, 15(Suppl. 3), iii34iii41. doi:10.1136/tc.2004.008748

Chan, Y. H. (2003). Biostatistics 104: Correlational analysis. Singapore Medical Journal, 44, 614-619.

Gilpin, E. A., Farkas, A. J., Emery, S. L., Ake, C. F., \& Pierce, J. P. (2002). Clean indoor air: Advances in California, 1990-1999. American Journal of Public Health, 92, 785-791. doi:10.2105/AJPH. 92.5.785 
Gwet, K. L. (2008). Computing inter-rater reliability and its variance in the presence of high agreement. British Journal of Mathematical and Statistical Psychology, 61, 29-48. doi:10.1348/ 000711006X126600

Heloma, A., \& Jaakkola, M. S. (2003). Four-year follow-up of smoke exposure, attitude and smoking behaviour following enactment of Finland's national smoke-free work-place law. Addiction, 98, 1111-1117. doi:10.1046/j.1360-0443.2003.00429.x

Holbrook, A. L., Green, M. C., \& Krosnick, J. A. (2003). Telephone versus face-to-face interviewing of national probability samples with long questionnaires: Comparisons of respondent satisficing and social desirability response bias. Public Opinion Quarterly, 67, 79-125. http://www.jstor.org/stable/3521667

Hurd, A. L., Mayer, J. A., Woodruff, S. I., Belch, G. E., \& Patel, M. R. (2006). Comparing two methods of measuring legislation compliance among indoor tanning facilities. Journal of the American Academy of Dermatology, 54, 433-439. doi:10.1016/ j.jaad.2005.11.1078

Hyland, A., Higbee, C., Borland, R., Travers, M., Hastings, G., Fong, G. T., et al. (2009). Attitudes and beliefs about secondhand smoke and smoke-free policies in four countries: Findings from the International Tobacco Control Four Country Survey. Nicotine \& Tobacco Research, 11, 642-649. doi:10.1093/ntr/ntp063

Inspectie voor de Gezondheidszorg. (2010). Jaarplan rijksinspecties ziekenhuizen (annual plan state inspectorates in hospitals). Internet. Retrieved from http://www.igz.nl/Images/Jaarplan\% 20rijkinspecties\%20ziekenhuizen\%202011tcm294-300052.pdf

Willemsen, M. C., Brug, J., Uges, D. R., \& Vos, de Wael, M. L. (1997). Validity and reliability of self-reported exposure to environmental tobacco smoke in work offices. Journal of Occupational and Environmental Medicine, 39, 1111-1114. doi:10.1097/00043764199711000-00012 